\title{
atherosclerosis
}

Atherosclerosis $126(1996) 155-161$

\section{Trans unsaturated fatty acids in plasma phospholipids and coronary heart disease: a case-control study}

\author{
Lucy P.L. van de Vijver,a,*, Geert van Poppel ${ }^{a}$, Adriana van Houwelingen ${ }^{\mathrm{c}}$, Dick \\ A.C.M. Kruyssen ${ }^{\mathrm{d}}$, Gerard Hornstra ${ }^{\mathrm{c}}$ \\ ${ }^{a}$ Department of Epidemiology, TNO Nutrition and Food Research, P.O. Box 360, 3700 AJ Zeist, Netherlands \\ ${ }^{\mathrm{b}}$ Department of Epidemiology and Biostatistics, Erasmus University, Rotterdam, Netherlands \\ 'Depariment of Human Biology, Limburg University, Maasiricht, Netherlands \\ ${ }^{ }$Zuiderziekenhuis, Rotterdam, Netherlands
}

Received 10 January 1996; revised 17 May 1996; accepted 20 May 1996

\begin{abstract}
A high intake of trans fatty acids (TFAs) has been shown to have an undesirable effect on serum lipid profiles and lipoprotein(a) (Lp(a)) levels and may thereby increase the risk for coronary heart disease (CHD). We performed a study in CHD patients, and measured the TFA concentration of the plasma phospholipid fraction. Comparison was made between a case group with angiographically documented severe $\mathrm{CHD}(>80 \%$ stenosis in one coronary vessel, $n=83$ ) and a control group of patients who had just minor stenosis on the coronary angiography ( $<50 \%$ stenosis in all three major vessels, $n=78$ ). All subjects were under 68 years of age and were prestratified on age, gender and smoking habits. The two groups were comparable according to the prestratification criteria, body mass index, blood pressure, number of cigarettes smoked and total fat intake. Controls had higher plasma HDL levels $(P<0.001)$ and lower, albeit not significantly lower, $(P=0.07)$ plasma LDL levels. No significant correlations were found between percentages of TFAs in plasma phospholipids and plasma LDL or HDL cholesterol levels. Of the major fatty acid classes, only the percentage of saturated fatty acids was significantly higher in cases $(46.2 \pm 0.92 \%)$ than in controls $(45.8 \pm 1.07 \%$ (means \pm S.D. $)$ ). The difference in total TFA content between cases and controls $(0.32 \pm 0.02 \%$ versus $0.35 \pm 0.02 \%)$ was $-0.03 \%(P=0.2)$. For the specific TFAs C16:1n-7tr, C18:1n-9tr and C18:2n-6tr, just minor differences were found. Adjusted odds ratios for tertiles of TFA percentages were $0.56(0.25-1.23)$ and 0.76 $(0.36-1.61)$ for the highest and middle tertile compared to the lowest. These findings do not support an association between TFA intake and risk for coronary heart disease.
\end{abstract}

Keywords: Trans fatty acid; Phospholipids; Coronary atherosclerosis

*Corresponding author. Tel.: + 3130 6944455; fax: + 3130 6957952; e-mail: vandeVijver@Voeding.TNO.NL 


\section{Introduction}

In order to produce dietary fats with better texture and stability, trans fatty acids (TFAs) are industrially produced by partial hydrogenation of vegetable oils. In this process double bonds are saturated and trans and cis isomers of oleic and linoleic acids are formed. Also, a contribution to TFA intake is provided by naturally occurring TFAs, formed in small amounts in the rumen of cattle.

Since recent studies have reported an undesirable effect of TFAs on serum lipid profiles [1-7] and lipoprotein(a) $(\mathrm{Lp}(\mathrm{a}))$ levels $[5,7,8]$, there is concern about the health risks for coronary heart disease (CHD). Up to now the evidence for a direct relationship between the uptake of TFAs and the incidence of CHD is limited. A large prospective study in women reported an increased risk for CHD [9] and a recent case-control study demonstrated an increased risk for myocardial infarction [10] with increasing TFA intake. In these studies, dietary TFA data were used to investigate a possible relationship. Because of limited information on TFA content of different food items and difficulty in measuring food intake, these data have been debated [11]. Studies using biomarkers for TFA intake may therefore be more informative.

We have now examined the relation between TFA and CHD in a case-control study, by comparing TFA concentrations of plasma phospholipids in a group carefully selected for angiographically documented severe CHD, and a control group who had just minor stenosis on the coronary angiography.

\section{Subjects and methods}

\subsection{Study population}

This study was conducted in 6 hospitals in Rotterdam, Netherlands, initially to study the relationship between angiographically documented CHD and cholesterol oxidation products. In the period 1991-1992, 1467 subjects had a coronary angiography for suspected CHD. Ineligible were subjects: over 68 years of age $(n=352)$; with a previous bypass surgery $(n=110)$; with a myocardial infarction in the 12 months prior to the study period $(n=143)$; under cardiac care for more then 2.5 years $(n=295)$; in whom more then 2 months elapsed between angiography and case selection ( $n=117)$; who had diabetes mellitus, liver, kidney or thyroid disease, or showed evidence of alcohol or drug abuse $(n=63)$. Of the remaining 387 subjects, 51 refused to participate, 22 could not be contacted or were otherwise indisposed and 7 had died. Of the remaining 307 subjects, cases were selected on the basis of having more then $80 \%$ stenosis in at least one of the three major coronary vessels and controls having less then $50 \%$ stenosis in all three major coronary vessels. Cases and controls were prestratified on age, gender and smoking habits. Controls who had experienced a myocardial infarction or underwent a percutaneous transluminal coronary angioplasty were excluded from the analysis. For six subjects no TFAs were analysed due to a lack of plasma. This left 157 subjects for data analysis ( 83 cases and 74 controls). In addition, data analysis was performed on controls with less then $10 \%$ stenosis in all three coronary vessels $(n=52)$ and cases with more then $80 \%$ stenosis in one and more than $70 \%$ stenosis in another coronary vessel $(n=44)$.

\subsection{Data collection}

Within 2 months after angiography, information was obtained, from the medical status and through a questionnaire, on medical history, use of medication, dietary, smoking and drinking habits, occupation and family history of CVD. Further data on height, weight and blood pressure were recorded. A fasting venous blood sample was collected in a $10 \mathrm{ml}$ EDTA vacutainer tube. Blood samples were immediately placed on ice and within $30 \mathrm{~min}$ the plasma was isolated by centrifugation. Within $2 \mathrm{~h}$ after venipuncture, the isolated plasma was stored at $-80^{\circ} \mathrm{C}$.

\subsection{Laboratory analysis}

After collection of all blood samples the fatty acid composition of the phospholipids was 
analysed as follows. Total lipid extraction was performed as described by Bligh and Dycr [12]. L- $\alpha$-dinonadecanoyl lecithin (PC 19:0) was used as an internal standard to calculate the quantitative amounts. The phospholipid (PL) fraction was separated by column chromatography according to Kaluzny et al. [13]. The PL fraction was hydrolysed and the fatty acids methylated with borontrifluoride. The fatty acid composition of the PL was then determined by gas chromatography as described by Mensink et al. [14]. The inter-assay coefficient for variation was $3.9 \%$.

Plasma HDL-cholesterol and triglyceride levels were determined as described by Sullivan et al. [15] and Warnick et al. [16], respectively. Totalcholesterol content of plasma was determined by use of a spectrum analyser (Abbott, USA) with CHOD-PAP reagent (cat. no. 236691, Boehringer, Mannheim). Plasma LDL-cholesterol was calculated with the Friedewald formula: LDLcholesterol = total-cholesterol - HDL-cholesterol $-0.45^{*} \mathrm{TG}[17]$.

\subsection{Data analysis}

Data analysis was conducted with the statistical package BMDP [18]. For all the analyses fatty acids were expressed as a percentage $(\mathrm{w} / \mathrm{w})$ of total fatty acid methyl esters in the phospholipids. Basic characteristics and percentages of fatty acids in cases and controls were compared by Student's $t$-test for unpaired samples $(P<0.05)$. Pearson $\chi^{2}$ analysis was applied for class variables. By means of the Pearson correlation coefficient the associations between fatty acids and continuous variables in the control group were quantified. To adjust differences in fatty acid concentrations between cases and controls for age. gender and smoking habits, multiple linear regression was used. Stratified analysis was performed to identify confounders or effect modifiers. Odds ratios were calculated to quantify the association betwecn TFA and coronary stenosis. The subjects were divided into tertiles based on total TFA concentrations in the control group. Multiple logistic regression adjusted the odds ratio for age, gender and smoking habits.

\section{Results}

Table 1 shows the basic characteristics of the 157 participants. HDL-cholesterol was significantly lower in cases than in controls. Further, cases more frequently reported use of a special diet, use of medicines and less frequent use of supplements.

Differences in mean fatty acid content of the phospholipids between cases and controls are presented in Table 2 . Only the percentage of saturated fatty acids was slightly though significantly higher in cases than in controls. This difference remained significant after adjustment for age, gender and smoking habits. For all other fatty acids, TFAs included, values were similar in cases and controls. TFAs accounted for only $0.08-1.02 \%$ of fatty acids in both cases and controls.

No associations were observed between the percentage TFAs and the following variables: age, body mass index, total, LDL and HDL cholesterol, triglycerides, use of lipid-lowering drugs (HMG-CoA reductase inhibitors), use of a special diet, use of supplements, history of myocardial infarction and subgroups of fatty acids (saturated, mono- and polyunsaturated, $n-3, n-6, n-9$ ).

Odds ratios were calculated for the tertiles of total TFA concentration (Table 3 ). There were only negligible differences when comparing the lowest with the middle or highest tertile of TFA concentration. Odds ratios calculated for the 3 groups of TFAs (C16:1n-7tr, C18:1n-9tr, C18:2n-6tr) yielded similar results.

\section{Discussion}

This study shows no association between trans fatty acid concentration in plasma phospholipids and angiographically documented coronary heart disease. It seems unlikely that this lack of an association is due to confounding factors in our study design. Both study groups were under cardiological treatment for vascular complaints and can thus be considered to be equally prone to dietary changes. Nevertheless, in this study more cases were on a cholesterol restricted diet. However, we observed no association between such a 
diet and TFA concentrations. Blood samples were taken within 2 months after catheterization, to prevent dietary changes after angiography from

Table 1

Baseline characteristics (mean \pm S.D.)

\begin{tabular}{|c|c|c|}
\hline & Controls $(n=74)$ & Cases $(n=83)$ \\
\hline Age (years) & $52.1 \pm 9.5$ & $54.3 \pm 8.6$ \\
\hline $\begin{array}{l}\text { Body mass index }(\mathrm{kg} / \\
\left.\mathrm{m}^{2}\right)\end{array}$ & $25.4 \pm 3.1$ & $26.2 \pm 3.0$ \\
\hline $\begin{array}{l}\text { Systolic blood pres- } \\
\text { sure }(\mathrm{mmHg})\end{array}$ & $131.2 \pm 16.6$ & $133.0 \pm 18.0$ \\
\hline $\begin{array}{l}\text { Diastolic blood pres- } \\
\text { sure (mmHg) }\end{array}$ & $83.0 \pm 10.4$ & $83.0 \pm 10.5$ \\
\hline $\begin{array}{l}\text { Under cardiac care } \\
\text { (years) }\end{array}$ & $0.66 \pm 0.42$ & $0.86 \pm 0.69$ \\
\hline $\begin{array}{l}\text { HDL-cholesterol } \\
(\mathrm{mmol} / \mathrm{l})\end{array}$ & $1.32 \pm 0.37$ & $1.08 \pm 0.30^{*}$ \\
\hline $\begin{array}{l}\text { LDL-cholesterol } \\
(\mathrm{mmol} / \mathrm{l})\end{array}$ & $3.92 \pm 1.00$ & $4.21 \pm 0.89$ \\
\hline $\begin{array}{l}\text { Total-cholesterol } \\
(\mathrm{mmol} / \mathrm{l})\end{array}$ & $5.92 \pm 1.07$ & $6.23 \pm 0.88^{* *}$ \\
\hline Triglyceride (mmol) & $1.51 \pm 0.86$ & $2.09 \pm 1.21^{*}$ \\
\hline $\begin{array}{l}\text { Total fatty acids in } \\
\text { phospholidpids } \\
(\mu \mathrm{g} / \mathrm{ml})\end{array}$ & $1454.5 \pm 236.9$ & $1514.0 \pm 249.7$ \\
\hline $\begin{array}{l}\text { Years after stopping } \\
\text { smoking }\end{array}$ & $11.3 \pm 11.5$ & $6.2 \pm 8.82^{* *}$ \\
\hline $\begin{array}{l}\text { Cigarettes/day (smok- } \\
\text { ers only) }\end{array}$ & $12.5 \pm 10.6$ & $12.4 \pm 9.4$ \\
\hline $\begin{array}{l}\text { Proportion }(\%) \text { of } \\
\text { Men }\end{array}$ & 68 & 68 \\
\hline Current smokers & 30 & 25 \\
\hline Fx-smokers & 49 & 67 \\
\hline $\begin{array}{l}\text { History of myocardial } \\
\text { infarction }\end{array}$ & 0 & $17^{* *}$ \\
\hline History of PTCA & 0 & $11 * *$ \\
\hline $\begin{array}{l}\text { History of hyperten- } \\
\text { sion }\end{array}$ & 38 & 43 \\
\hline $\begin{array}{c}\text { Family history of car- } \\
\text { diovascular disease }\end{array}$ & 66 & 69 \\
\hline Supplement users & 27 & $13^{* *}$ \\
\hline Special diet & 15 & $40^{*}$ \\
\hline $\begin{array}{l}\text { Cholesterol-re- } \\
\text { stricted }\end{array}$ & 4 & 24 \\
\hline Fat-restricted & 8 & 8 \\
\hline Medication users & 78 & $98 *$ \\
\hline $\begin{array}{l}\text { Anti-hypertensive } \\
\text { drugs }\end{array}$ & 69 & 82 \\
\hline $\begin{array}{l}\text { Lipid-lowering } \\
\text { drugs }\end{array}$ & 7 & $24^{* *}$ \\
\hline Alcohol users & 76 & 70 \\
\hline
\end{tabular}

${ }^{*} P<0.001,{ }^{* *} P<0.05$. influencing dietary TFA intake. After angiography change in diet was reported in 6 cases and 4 controls, of whom 2 subjects in both groups reported use of a cholesterol or fat lowering diet. Our results were essentially similar after we excluded these subjects.

In this study, cases were shown to use more medication. No association was found between percentage TFAs and the use of several medications; subanalysis with exclusion of users yielded the same results.

Both cases and controls underwent coronary angiography. As both groups had an indication for angiography, our study population may not be representative of the general population. Application of a control group with angiographically documented minor stenosis, however, has the advantage of a well defined objective measure for coronary stenosis. The control group, nonetheless, also includes subjects with known (minor) stenosis which may obscure a relation between coronary stenosis and TFAs. The mean percentage stenosis ( \pm S.D.) was $5.6 \% \pm 8.3 \%$ in the control and $60.6 \pm 19.9 \%$ in the case group. In the control group, the mean percentage stenosis in the 3 major vessels did not exceed $30 \%$. To enhance the contrast between cases and controls we analysed a sub-group of controls with $\leq 10 \%$ stenosis $(n=$ 52 ) in all three major vessels and cases with $\geq 80 \%$ in one and $\geq 70 \%$ stenosis in another coronary vessel $(n=44)$. The percentage fatty acids calculated in this subgroup were essentially similar to those reported in Table 2 , no difference was seen for TFAs $(0.33 \pm 0.02 \%$ in cases versus $0.37 \pm$ $0.03 \%$ in controls), and only the amount of saturated fatty acids was significantly higher in the case group.

TFA were assessed in the phospholipid fraction, which is a relatively stable lipid class, whose fatty acid composition is less responsive to shortterm dietary changes than other lipid fractions in plasma. Therefore, the amount of phospholipids of those fatty acids that cannot be synthesized by man, present a reliable estimate of the dietary intake of these fatty acids in the period surrounding the blood sampling [14]. As atherosclerosis is a slowly developing process, from these results we cannot exclude previous variations in TFA intake 
Table 2

Percentages and adjusted differences of major fatty acid groups in phospholipids in controls with minor and cases with severe stenosis (mean \pm S.E.M.)

\begin{tabular}{lcccc}
\hline Fatty acid & Controls $(n=74)$ & Cases $(n=83)$ & $P$-value & Adjusted difference $^{a}$ \\
\hline Saturated & & & \\
$n-3$ & $45.81 \pm 0.12$ & $46.18 \pm 0.10$ & 0.02 & $0.38 \pm 0.16(P=0.02)$ \\
$n-6$ & $5.40 \pm 0.15$ & $5.52 \pm 0.17$ & 0.76 & $0.09 \pm 0.24$ \\
$n-7$ & $35.40 \pm 0.26$ & $35.38 \pm 0.29$ & 0.97 & $-0.03 \pm 0.41$ \\
$n-9$ & $1.44 \pm 0.03$ & $1.37 \pm 0.03$ & 0.08 & $-0.07 \pm 0.04$ \\
Polyunsaturated & $9.50 \pm 0.15$ & $9.27 \pm 0.14$ & 0.26 & $-0.22 \pm 0.21$ \\
Monounsaturated & $41.00 \pm 0.17$ & $41.09 \pm 0.17$ & 0.75 & $-0.04 \pm 0.25$ \\
Total TFA & $10.92 \pm 0.16$ & $10.62 \pm 0.16$ & 0.17 & $-0.01 \pm 0.03$ \\
C16: $1 n-7 \mathrm{tr}$ & $0.35 \pm 0.02$ & $0.32 \pm 0.02$ & 0.22 & $-0.00 \pm 0.00$ \\
C18: $1 n-9 \mathrm{t}$ - & $0.03 \pm 0.002$ & $0.02 \pm 0.002$ & 0.10 & $-0.01 \pm 0.02$ \\
C18:2n-6tr & $0.30 \pm 0.02$ & $0.28 \pm 0.01$ & 0.31 & $-0.00 \pm 0.00$ \\
Unknown & $0.02 \pm 0.002$ & $0.02 \pm 0.001$ & 0.36 & $-0.11 \pm 0.11$ \\
\hline
\end{tabular}

adjusted for age, gender, smoking status and use of cholesterol or fat restricted diet.

${ }^{\mathrm{b}}$ Saturated $=$ all saturated fatty acids, $n-3(6,7,9)=$ all fatty acids of $n-3(6,7,9)$ family.

as risk factor for the development of atherosclerosis.

No associations between TFA concentrations and plasma LDL and HDL cholesterol levels have

\section{Table 3}

Crude and adjusted odds ratios for having severe coronary stenosis in tertiles of phospholipid trans fatty acids in 81 cases and 74 controls

\begin{tabular}{|c|c|c|c|}
\hline Tertiles & Low & Mediun: & High \\
\hline \multicolumn{4}{|c|}{ Crude OR $(95 \% \mathrm{CI})$} \\
\hline Total TFA & 1.0 & $\begin{array}{l}0.72(0.34- \\
1.54)\end{array}$ & $\begin{array}{l}0.61(0.28- \\
1.33)\end{array}$ \\
\hline $\mathrm{C} 16: 1 n-7 \mathrm{tr}$ & 1.0 & $\begin{array}{l}0.56(0.26- \\
1.23)\end{array}$ & $\begin{array}{l}0.69(0.32- \\
1.48)\end{array}$ \\
\hline $\mathrm{C} 18: \ln -9 \mathrm{tr}$ & 1.0 & $\begin{array}{l}0.97(0.46- \\
2.06)\end{array}$ & $\begin{array}{l}0.74(0.34- \\
1.63)\end{array}$ \\
\hline $\mathrm{C} 18: 2 n-6 \mathrm{tr}$ & 1.0 & $\begin{array}{l}1.37(0.65- \\
2.90)\end{array}$ & $\begin{array}{l}0.73(0.32 \\
1.66)\end{array}$ \\
\hline \multicolumn{4}{|c|}{ Adjusted OR $(95 \% \mathrm{Cl})^{\mathrm{a}}$} \\
\hline $\begin{array}{l}\text { Total trans } \\
\text { fatty acids }\end{array}$ & 1.0 & $\begin{array}{l}0.73(0.33- \\
1.59)\end{array}$ & $\begin{array}{l}0.69(0.31- \\
1.57)\end{array}$ \\
\hline $\mathrm{C} 16: 1 n-7 \mathrm{tr}$ & 1.0 & $\begin{array}{l}0.60(0.26- \\
1.35)\end{array}$ & $\begin{array}{l}0.78(0.35- \\
1.73)\end{array}$ \\
\hline $\mathrm{C} 18: \ln -9 \mathrm{tr}$ & 1.0 & $\begin{array}{l}0.96(0.44- \\
2.11)\end{array}$ & $\begin{array}{l}0.86(0.38 \\
1.96)\end{array}$ \\
\hline $\mathrm{C} 18: 2 n-6 \mathrm{tr}$ & 1.0 & $\begin{array}{l}1.52(0.68- \\
3.37)\end{array}$ & $\begin{array}{l}0.78(0.32- \\
1.88)\end{array}$ \\
\hline
\end{tabular}

adjusted for age, gender, smoking habits and use of cholesterol or fat restricted diet. been found. This is in contrast to several dietary intervention studies showing significant effects of TFA intake on LDL and HDL cholesterol levels [1-7]. It should be recalled, however, that these effects are clearly dose-dependent [19], and since the habitual intake of TFAs in the Netherlands (approximately $2 \mathrm{En} \%$, see Ref. [14]) is lower than the amounts used in several of these studies, the 'exposure range' in our present study may have been too small to observe a relation between TFAs and cholesterol levels. In the USA, mean TFA intake has been estimated at $8 \mathrm{~g}$ per day [20], which would be slightly over $2 \%$ of energy intake [21].

Studies on the relationship between TFA and the risk of CHD are limited. Our results support the findings from Europe, recently published by Aro et al. [22], Roberts et al. [23] and an earlier study by Thomas et al. [24]. In these studies, no consistent relation was observed between the amounts of TFAs in fat biopsies and the occurrence of myocardial infarction. This is in contrast to results of studies in the USA by Willett et al. [9], $\Lambda$ scherio et al. [10] and Siguel et al. [25]. However, the study of Roberts et al. [23] was relatively small and, consequently, the confidence intervals were so wide that even diabetes mellitus and hypertension were not recognized as significant risk factors for cardiovascular mortality. In 
addition, the results of the trans analysis in the Euramic study [22] indicate that trans intake in Europe is lower than in the USA, which, again, raises the question whether the exposure range in Europe is sufficient to observe statistical significant differences. On the other hand, Willett et al. and Ascherio et al. made use of TFA intake data $[9,10]$. Dietary intake is difficult to measure and data on TFA contents of different food items are still limited. Therefore, the reliability of TFA calculations from these data may be questioned. Siguel et al. [25] measured plasma levels of TFAs in total lipids. These USA data for total plasma lipids are about 3-4 times higher than our data for phospholipids (1.11\% for controls and 1.38\% for cases versus $0.35 \%$ and $0.32 \%$ in our population). Since trans fatty acids are about $60-90 \%$ higher in plasma triglycerides and cholesterol esters than in phospholipids [26], this observation again indicates a substantially higher trans intake in the USA as compared to Europe. Siguel and co-workers found a significant difference in TFA concentration between subjects with angiographically documented coronary stenosis and population controls. However, the sample size was small and information on coronary vascular disease or coronary stenosis in the population controls was lacking. Further, the reported contrast may very well reflect short-term dietary changes towards more vegetable and TFA containing products upon vascular complaints $[21,27]$. In contrast to the European dietary margarines, the US dietary margarines contain a considerable amount of TFA [28], which may enlarge the difference between cases and population controls.

In conclusion, our results using a biomarker suggest that trans fatty acid intake at levels occurring in the Netherlands is not associated with coronary stenosis.

\section{Acknowledgements}

This study was supported by the Netherlands Heart Foundation. The authors wish to thank Mrs. A. Legters for enthusiastic and skilful data collection. The following hospitals and cardiologists in Rotterdam are thanked for their participa- tion in this study: Zuiderziekenhuis (C.J. Storm); St. Clara Ziekenhuis (F.M.A. Harms, R. Wardeh); IJsselland Ziekenhuis (W.M. Muijs van de Moer); St. Franciscus Gasthuis (R. van Mechelen); Ikazia Ziekenhuis (M.P. Freericks); Ruwaard van Putten Ziekenhuis (G.J. van Beek).

\section{References}

[1] Mensink RP, Katan MB. Effect of dietary trans fatty acids on high-density and low-density lipoprotein cholesterol levels in healthy subjects. $\mathrm{N}$ Engl $\mathrm{J}$ Med 1990;323:439.

[2] Katan MB, Mensink RP. Isomeric fatty acids and serum lipoproteins. Nutr Rev 1992;50:46.

[3] Troisi R, Willett WC, Weiss ST. Trans fatty acid intake in relation to serum lipid concentrations in adult men. Am J Clin Nutr 1992;56:1019.

[4] Zock PL, Katan MB. Hydrogenation alternatives: effects of trans fatty acids and stearic acid versus linoleic acid on serum lipids and lipoproteins in humans. J Lipid Res 1992;33:399.

[5] Nestel P, Noakes M, Belling B, McArthur R, et al. Plasma lipoprotein lipid and $L$ p(a) changes with substitution of elaidic acid for oleic acid in the diet. J Lipid Res 1992;33:1029.

[6] Lichtenstein AH, Ausman LM, Carraxo W, Jenner JL, Ordovas JM, Schaefer EJ. Hydrogenation impairs the hypolipidemic effect of corn oil in humans. Hydrogenation, trans fatty acids, and plasma lipids. Arterioscler Thromb 1993;13:154.

[7] Judd JT, Clevidence A, Muesing RA, Wittes J, Sunkin ME, Podczasy JJ. Dietary trans fatty acids: effects on plasma lipids and lipoproteins of healthy men and women. Am J Clin Nutr 1994;59:861.

[8] Mensink RP, Zock PL, Katan MB, Hornstra G. Effect of dietary cis and trans fatty acids on serum lipoprotein(a) levels in humans. J Lipid Res 1992;33:1493.

[9] Willett WC, Stampfer MJ, Manson JE, et al. Intake of trans fatty acids and risk of coronary heart disease among women. Lancet 1993;341:581.

[10] Ascherio A, Hennekens CH, Buring JE, Master C, Stampfer MJ, Willett WC. Trans fatty acids intake and risk of myocardial infarction. Circulation 1994;89:94.

[11] McKeigue P. Trans fatty acids and coronary heart disease: weighing the evidence against hardened fat (commentary). Lancet 1995;345:269.

[12] Bligh ED, Dyer WJ. A rapid method for total lipid extraction and purification. Can J Biochem Physiol 1959;37:911.

[13] Kaluzny MA, Duncan LA, Merritt MV, Epps DE, Rapid separation of lipid classes in high yield and purity using bonded phase columns. J Lipid Res 1985;26:135. 
[14] Mensink RP, Hornstra G. The proportion of trans monounsaturated fatty acids in serum triacylglycerols or platelet phospholipids as an objective indicator of their short-term intake in healthy men. $\mathrm{Br} \mathrm{J}$ Nutr 1995;73:605.

[15] Sullivan DR, Kruijswijk Z, West CE, Kohlmeier M, Katan MB. Determination of serum triglycerides by an enzymatic method not affected by free glycerol. Clin Chem 1985;31:1227.

[16] Warnick GR, Benderson J, Albers JJ. Dextran sulfate $\mathrm{Mg}$ precipitation procedure for quantitation of high-density lipoprotein cholesterol. Clin Chem 1982;28:1379.

[17] Friedewald WT, Levy R and Fredrickson DS. Estimation of the concentration of LDL-cholesterol in plasma without the use of the preparative ultracentrifuge. Clin Chem 1972;18:499.

[18] Dixon WJ ed. BMDP statistical software manual version 7.0, California 1992.

[19] Katan MB, Zock PL, Mensink RP. Trans fatty acids and their effects on lipoproteins in humans. Annu Rev Nutr 1995;15:473.

[20] Hunter JE, Applewhite TH. Reassessment of trans fatty acid availability in the US diet. Am $J$ Clin Nutr 1991;54:363.

[21] Longnecker MP. Do trans fatty acids in margarine and other foods increase the risk of coronary heart disease? Epidemiology 1993;4:492.
[22] Aro A, Kardinaal AFM, Salminen I, et al. Adipose tissue isomeric trans fatty acids and risk of myocardial infarction in nine countries: the EURAMIC study. Lancet 1995;345:273.

[23] Roberts TL, Wood DA, Riemersma RA, Gallagher PJ, Lampe FC. Trans isomers of oleic and linoleic acids in adipose tissue and sudden cardiac death. Lancet 1995;345:278.

[24] Thomas LH, Winter JA, Scott RG. Concentration of 18:1 and 16:1 trans unsaturated fatty acids in the adipose body tissue of decendents dying of ischaemic heart disease compared with controls: analysis by gas liquid chromatography. J Epidemiol Commun Health 1983;37:16.

[25] Siguel EN, Lerman RH. Trans fatty acid patterns in patients with angiographically documented coronary artery disease. Am J Cardiol 1993;71:916.

[26] Koletzko B. Trans fatty acids may impair biosynthesis of long-chain polyunsaturates and growth in man. Acta Paediatr 1992;81:302.

[27] Willett WC, Ascherio A. Trans fatty acids: are the effects only marginal? (commentary). Am J Publ Health 1994:84:722.

[28] Michels K, Sacks F. Trans fatty acids in European margarines (letter to the editor). $\mathrm{N}$ Engl $\mathrm{J}$ Med 1995;332:541. 